garten is of opinion that it is very probably identical with the streptococcus pyogenes, but cultivations are still wanting.

Septicemia consecutive to anthrax.-Charrin found cocci in rabbits, examined some hours after death, from anthrax. These, when isolated, produced death in rabbits from septicæma without suppuration. Chains composed of from fifteen to twenty elements were found in all the organs. This was probably another instance of streptococcus pyogenes.

Pycmia and septicamia.-Rosenbach examined six cases of pyæmia. From Case 1 cultivations of streptococcus pyogenes were obtained from the blood of the patient during life. The blood was stroked over the surface of the culture medium, and in two tubes the staphylococcus pyogenes aureus was also present. In Case 2, with suppurative pleuritis, the pleura was tapped during life, and cultivations of streptococcus pyogenes were obtained. In Case 3 streptococci were found in the metastases in the kidneys and in the other suppurations that were examined. In Case 4 the pleura was opened during life, and a streptococcus pyogenes associated with staphylococcus pyogenes aureus was cultivated from the fluid which escaped. In Case 5 pure cultivations of streptococcus pyogenes were obtained from pus from the knee, which was punctured during life. This case was one of erysipelas and pyæmia after removal of a carcinoma of the breast. In Case 6, a case of whitlow with metastatic abscesses, the patient recovered, and no streptococci were found. Thus, in six cases of metastatic pyæmia streptococcus pyogenes was found five times, partly in the blood and partly in the metastatic deposits, and twice in company with staphylococcus pyogenes aureus.

Baumgarten also found the streptococcus pyogenes in the internal organs in pyæmic cases, and Elselsberg found streptococcus pyogenes in company with staphylococcus pyogenes aureus in the blood of cases of septicamia.

Congenital syphilis. - Kassowitz and Hochsinger found the presence of a streptococcus in the tissues and internal organs, and especially in the bloodvessels, in fatal cases of congenital syphilis. These observers regarded their discovery as having an important bearing on the etiology of syphilis, but Kolisko pointed out that it was only the result of septic infection with presence of streptococcus pyoyenes, as had already been established in scarlet fever.

Idiopathic cerebro-meningitis.-From the meningeal exudation of a case of apparently idiopathic cerebro-meningitis Banti found by Koch's methods the presence of streptococcus pyogenes and staphylococcus aureus and albus. The cocci probably entered through an abscess of the jejunum.

Blepharadenitis and phlegmonous dacryocystis.-Widmark isolated by cultivations streptococcus pyogenes and other organisms from these diseases. In phlegmonous dacryocystis Widmark found streptococcus pyogenes almost exclusively.

Fatal case of leukcemia.-Flugge cultivated a streptococcus from necrotic patches in the spleen of a fatal case of leukæmia. Cultures corresponded very closely with streptococcus pyogenes. Inoculation in the ears of rabbits produced similar results to streptococcus pyogenes or erysipelatis. Flügge calls it streptococcus pyogenes malignus, but concludes that it is probably identical with the streptococcus from pus.

Earth.-Nicolaier, and later Guarneri, isolated a streptococcus from soil. Microscopically it could not be distingui ohed from other streptococci. Baumgarten is of opinion that it is neither in form nor in cultivation to be distinguished with certainty from streptococcus pyogenes.

Air.-Emmerich succeeded in proving the presence of chain cocci in the air of a hospital where erysipelas had broken out. These cocci in their form, their characters on cultivation, and in inoculation results were identified with the streptococcus erysipelatis.

Various rotting substances.--Baumgarten states that in the most various substances undergoing putrefaction streptococci are always found, which morphologically are exactly similar to the streptococcus erysipelatis. Baumgarten, therefore, regards it as quite possible that the streptococcus erysipelatis or pyogenes is essentially a saprophytic organism - that is to say, an organism which may be found wherever there is decaying organic matter, - and that its parasitism is only incidental.

\section{NATCRE OF CONTAGICX IN THE GXANTHENATA} CNDETERMINED.

I think, therefore, that the results of these numerous investigations constitute a wass of evidence in support of my opinion that in a disease which is accompanied with a lesion of the skin or mucous membrane, and in which the blood and tissues are profoundly affected by the virus of that disease, micro-organisms may gain an entrance into the circulation and escape destruction. The occurrence therefore, of streptococcus pyogenes in diphtheria, scarlet fever, vaccinia, variola, measles, typhoid fever, \&c., must be regarded as a secondary result, and associated with septic or pyæmic complication; and I am forced to the conclusion that, excepting negative evidence, bacteriology hasnot assisted us in the least in the determination of the real nature of the morbific agent or actual contagium of the exanthemata. That there are certain diseases which are due to microorganisms is, 1 am sure, accepted by all modern pathologists, but we are far from having solved the nature of the contagium of all communicable diseases. In many cases, as in hydrophobia, where bacteria have been brought forward as the specific agents, they have been gradually substituted by the less definable term virus. Misapplied bacteriology will be both misleading and mischievous, and this criticism is applicable if a micro-organism is maintained to be the actual contagium of a disease, such as scarlatina, in the face of obvious fallacies, and without affording the evidence which is usually regarded as necessary for admitting a causal connexion.

( $T$ o be concluded.)

\section{CUlinical a atos:}

\section{MEDICAL, SURGICAL, OBSTETRICAL, AND THERAPEUTICAL.}

\section{ERGOTININ IN A CASE OF HAMOPTYSIS,}

\section{BY JohN Cochrane, L.R.C.P. \& L.R.C.S.E.,} MEDICAL OFFICER OF THE PARISH OF STRATH, SKYE.

I AM anxious to bring under the notice of your readers an incident which happened in my practice lately, and I should be glad to know whether the case which I am about to relate has happened previously.

I was called to see a middle-aged married woman residing near me, and found her confined to bed and suffering from an attack of pretty severe hæmoptysis. She had been seized with this illness three days previously to my being called in, and, judging from the statements of her husband, she must have lost a considerable quantity of blood. I found her in a weak state and coughing continually, and each time ejected a large amount of bright blood mixed with expectoration. There was no feverishness, but, owing to the coughing, she had been unable to retain much, if any, food in her stomach. Thinking this a favourable case for the administration of ergotinin, I immediately gave a hypodermic injection over the chest, and as soon as this had been done my patient suddenly went off into a state of syncope, and had all the appearance of having suddenly expired; her face assumed a death-like appearance, and I could feel no pulse at the wrist. I immediately slapped her face with cold water, and rubbed her chest. At the same time I told her husband, who was in the room, and who was in a terribly frantic state, to bring $\mathrm{m} \theta$ some brandy or whisky, and also to get some bottles filled with hot water to apply to her feet and legs. Waiting the result anxiously, I was glad to find her beginning to show signs of returning animation, and after a while she gradually opened ber eyes. The colour also began to return to her face and lips, and then in a few minutes further she vomited freely a quantity of halfdigested food mixed with bile. She recovered entirely, and the cough disappeared as well. The bleeding from the lungs also was entirely stopped, and not a drop appeared after the injection. There bas been no return of cough or bæmorrhage since then, now several months ago, and the patient is going about seemingly in very good health. When called to see her, I found beside the bed a vessel half filled with bright-red blood. There is a history of phthisis in her family, several brothers and sisters having died of this disease, and she is the last surviving of the family.

Now, I would like to inquire what, was the cause of the sudden attack of syncrpe in this case following so closely 
the injection of the ergotinin. Was it in any way due to the drug, or was it the result of fright reacting on a highly nervous and weakly female? I am not quite able to come to a proper explanation of the case, but I am inclined to regard the alarming symptoms as due to the toxic action of ergot. Undoubtedly this drug sometimes gives rise to considerable nausea, and such may have been its action in this case. I should like the matter to be explained, as I am not quite satisfied that we can safely use this arrug in every case of hæmorrhage. The dose administered was 1-150 gr., and was in the form of a tabloid.

\section{CASES OF DISEASE COMMUNICATED TO HUMAN BELNGS FROM THE COW.}

By H. Malitins, A.B., M.B., M.CH. UnIv. Dub.

ABOUT six weeks ago five of Mr. P__ 's children began to complain of sore mouths, characterised by the appearance of small blister-like vesicles on the tongue and mucous membrane of the mouth. The milk, of which they partook freely, being suspected to be the cause of the mouth affection, an inquiry elicited the fact that one of the cows was suffering from a "humour" all over its body. The man in charge of the cow describes this rash as having presented the appearance of small red pimples, and as having been of a dry nature, except in the case of one small vesicle of the size of a threepenny piece which appeared on one of the teats. This vesicle dried up in a day or two, and did not seem to cause any inconvenience to the animal, whose health seemed so little the worse that the man did not think it worth while to inform his master of the appearance of the rash. The cow was at once isolated, and its milk having been kept separate from that of the other cows, it was noticed to have a distinctly greyish colour, "as if ink had been mixed with it." Later on the animal's skin desquamated freely. It is now in good health. The mouth affection yielded to treatment in a few days. Three weeks later, however, the sufferers from it began to display a peculiar skin affection in different parts of their bodies. Each spot began like an ordinary small boil, with red areola and elevated head. The head, however, instead of being yellow, was formed by a tiny flat vesicle with limpid contents. This vesicle daily increased in size until the third or fourth day, when the contained fluid changed to a white semi-solid pus, which by its accumulation detached the epithelial covering of the vesicle, leaving a raised ulcer-like sore, over which the pus dried into a firm crust, on the falling off of which the skin was found to be cicatrised, a smooth dark-red stain marking the site of the vesicle. The number of vesicles was limited, varying in the different cases from two or three to two dozen. Their size varied from that of a split pea to that of florin. The children became rather weak and anæmic while suffering from the eruption, but there was no marked constitutional disturbance.

Remarks. -There can be but little doubt that these children were the subjects of milk-communicated disease. It would appear that the milk, having had in the first instance a locally irritant action on the mucous membrane of the mouth, conveyed the germs of a disease which, after an incubatory period of at least two weeks, manifested itself in the shape of a vesicular eruption. There is a considerable degree of likeness between this eruption and that described by Professor Crookshank in his paper on the Hendon Cow Disease as having occurred amongst some of the milkers of "an infected herd." It is noteworthy that in the above cases the disease in the cow took chiefly the form of a red rash, while in the human being it displayed a vesicular nature.

\section{ADMINISTRATION OF COCAINE INTERNALLY IN REFLEX VOMITING.}

By Matthew Cursham Corner,

VISITIYG MEDICAI OFFICER TO THE LXING-IN HOME, SHADWELL.

ON Oct. 3rd, 1887, I received an urgent message to visit a lady living in the north of London, she having been ill for some days. On my arrival I found her to be in an exceeding prostrate condition, suffering from incessant vomiting and distressing retching, and unable to retain even icewater. I prescribed a freshly prepared mixture of bismuth, also ordered small pills of carbolic acid (one grain each). I saw her again that day, and finding her condition worse $I$ discontinued all nourishment and medicines by the mouth, and ordered counter-irritants over the epigastrium and nutrient enemata. The following day she was much weaker, the distressing retching continuing. Becoming anxious, I decided on having a second opinion; but before doing so, and having my hypodermic case with me, I gave her five minims of a 20 per cent. solution of cocaine in a teaspoonful of cold water, taken slowly. The effect was decisive. She went off into a calm sleep for over two hours, awaking with a slight feeling of nausea. I then left, leaving three doses of the same quantities to be given according to symptoms, with intervals of two or three hours. Being busy, I did not see her until late the following day, when I found her considerably improved.

$\mathrm{My}$ object in reporting this case is to ask if the relief afforded was due to the cocaine, or to nature causing profound exhaustion followed by refreshing sleep? I attributed the vomiting to dysmenorrhoea, possibly enhanced by stimulants taken to relieve pain, and that the pain was doubtless relieved by the flow which occurred at the beginning of her illness. As far as my experience goes, this is the first instance in which $I$ havie administered cocaine internally. In my maternity practice I use suppositories containing three grains each of cocaine, and have found great relief experienced in those cases undergoing the agonising pains common to the latter part of the first and beginning of the second stages of labour. Under my direction, the lady superintendent of the Shadwell Lying-in Home, has used them in cases of primiparæ, with happy results.

\section{g. 进litroror}

\section{OF \\ HOSPITAL PRACTICE, BRITISH AND FOREIGN.}

Nulla autem est alia pro certo noscendi via, nisi quamplurimas et morborum et dissectionum historias, tum aliorum tum proprias collectas habere, et inter se comparare-MoRgaGNI De Sed. et Caus. Morb. ib. iv. Procemium.

\section{UNIVERS1TY COLLEGE HOSPITAL.}

NEPHROTOMY; CALCULI THRICE REMOVED; ULTIMATELY NEPHRECTOMY; RECOVERY OF THE PATIENT.

(Under the care of Mr. Berkelex HILL.)

THE remarks which are appended to this case indicate the principal points to which we would draw attention in the clinical history, and it is rarely that we can give this so completely. The patient is now, we are informed by $\mathbf{M r}$. Berkeley Hill, gaining in weight, and is in good health, although the continued presence of albuminuria makes serious disease of the right kidney probable.

M. W - aged twenty-seven, labourer, was admitted on Nov. 25th, 1886. He complained of having had pain in the left side for fifteen years. The pain at first was felt daily; then became less and less frequent, till it was felt only at intervals of three or four months. The pain was always referred to the same spot in the loin, occasionally shooting to the testicle, and was of agonising severity. Micturition did not affect the pain, nor did it increase in frequency. During the last fortnight before admission the pain had been continuous, occasionally with nausea and faintness during a severe spasm. For six months there had been a deposit in the urine, but never blood. Now the urine has about 1-28th of a granular deposit; no blood nor stringy mucus. It is acid, sp. gr. 1011, with traces of albumen, and 1.6 per cent. of urea. After ten deys in hospital the urea increased to 4 or 46 per cent. Fulness could be felt in the left loin on deep inspiration by the fingers placed below the last rib. This pressure causes pain at the seat of the spasmodic pain long felt.

On Dec. 1st the left kidney was reached by a lumbar incision. It was small and very firm to the touch. The exploring needle immediately struck a stone. The kidney was incised, and the stone removed with the finger from a calyx. No other calculus was discovered by the finger or by the needle. The pelvis and calyces were not obvioualy 